\title{
Fabrication of Novel Hydrogel with Berberine-Enriched Carboxymethylcellulose and Hyaluronic Acid as an Anti-Inflammatory Barrier Membrane
}

\author{
Yu-Chih Huang, ${ }^{1}$ Kuen-Yu Huang, ${ }^{2}$ Bing-Yuan Yang, ${ }^{3}$ Chun-Han Ko, ${ }^{3}$ \\ and Haw-Ming Huang ${ }^{1,2,4}$ \\ ${ }^{1}$ School of Dentistry, College of Oral Medicine, Taipei Medical University, Taipei, Taiwan \\ ${ }^{2}$ Graduate Institute of Biomedical Materials and Tissue Engineering, College of Biomedical Engineering, \\ Taipei Medical University, Taipei, Taiwan \\ ${ }^{3}$ School of Forestry and Resource Conservation, National Taiwan University, Taipei, Taiwan \\ ${ }^{4}$ Graduate Institute of Biomedical Optomechatronics, College of Biomedical Engineering, Taipei Medical University, \\ Taipei, Taiwan
}

Correspondence should be addressed to Chun-Han Ko; chunhank@ntu.edu.tw and Haw-Ming Huang; hhm@tmu.edu.tw

Received 4 October 2016; Accepted 1 December 2016

Academic Editor: Jung-Wei Chen

Copyright (c) 2016 Yu-Chih Huang et al. This is an open access article distributed under the Creative Commons Attribution License, which permits unrestricted use, distribution, and reproduction in any medium, provided the original work is properly cited.

\begin{abstract}
An antiadhesion barrier membrane is an important biomaterial for protecting tissue from postsurgical complications. However, there is room to improve these membranes. Recently, carboxymethylcellulose (CMC) incorporated with hyaluronic acid (HA) as an antiadhesion barrier membrane and drug delivery system has been reported to provide excellent tissue regeneration and biocompatibility. The aim of this study was to fabricate a novel hydrogel membrane composed of berberine-enriched CMC prepared from bark of the P. amurense tree and $\mathrm{HA}(\mathrm{PE}-\mathrm{CMC} / \mathrm{HA})$. In vitro anti-inflammatory properties were evaluated to determine possible clinical applications. The PE-CMC/HA membranes were fabricated by mixing PE-CMC and $\mathrm{HA}$ as a base with the addition of polyvinyl alcohol to form a film. Tensile strength and ultramorphology of the membrane were evaluated using a universal testing machine and scanning electron microscope, respectively. Berberine content of the membrane was confirmed using a UVVis spectrophotometer at a wavelength of $260 \mathrm{~nm}$. Anti-inflammatory property of the membrane was measured using a Griess reaction assay. Our results showed that fabricated PE-CMC/HA releases berberine at a concentration of $660 \mu \mathrm{g} / \mathrm{ml}$ while optimal plasticity was obtained at a $30: 70 \mathrm{PE}-\mathrm{CMC} / \mathrm{HA}$ ratio. The berberine-enriched PE-CMC/HA had an inhibited $60 \%$ of inflammation stimulated by LPS. These results suggest that the PE-CMC/HA membrane fabricated in this study is a useful anti-inflammatory berberine release system.
\end{abstract}

\section{Introduction}

An antiadhesion barrier is one of the essential requirements for maintaining health and protecting tissue from postsurgical complications. For example, an antiadhesion barrier membrane is essential after intra-abdominal surgery to prevent normally free-moving tissues from sticking together [1]. For successful dental implant surgery, it is important to maintain adequate alveolar ridge dimensions and it often requires guided bone regeneration (GBR). This surgical procedure uses barrier membranes [2] that are often manufactured using expanded polytetrafluoroethylene (e-PTFE) [3, 4]. However, clinical and experimental studies have demonstrated that complications such as incomplete coverage or gingival recession can occur when this nonresorbable material is used for GBR [5-7]. Accordingly, bioresorbable polymeric membranes, such as polylactides and polyglycolides, were developed to replace nonresorbable membranes. The advantage of bioresorbable membranes is the elimination of the need for membrane removal giving the surgical procedure 
greater time-effectiveness. However, it was reported that polymeric membranes are greatly associated with inflammatory reactions [8]. Collagen has been recently introduced as a GBR membrane material because it can overcome the disadvantages of previous nonresorbable polymeric membranes [9, 10]. However, the speed of collagen membrane degradation is a concern when fabricating barrier membranes [11].

Recently, several natural polymers have been used to fabricate hydrogel tissue barriers. Among these natural polymers, hyaluronic acid (HA) [12] and cellulose [13] are two ubiquitous and abundant biopolymers used for tissue engineering and regenerative medicine. To produce inexpensive GBR membranes that can be easily manipulated, carboxymethylcellulose (CMC) and HA were used. CMC is a polysaccharide based hydrogel that when incorporated with hydroxyapatite in a CMC-based hydrogel provides excellent tissue engineering function [14]. In 2013, Sagar et al. developed a nanohydroxyapatite/gelatin and chemically carboxymethylated chitin scaffold that enhanced osteoblastic activity and mineralization [15]. However, cellulose-based hydrogels lack good mechanical proprieties for clinical use [14].

Hyaluronic acid is a natural component found in abundance in the extracellular space [16] and load-bearing joints $[17,18]$ that has been reported to play an important role in wound healing and for retaining skin moisture [19]. In addition, it has anti-inflammatory, antioxidant, and antibacterial effects for the treatment of periodontal diseases [20]. However, the lubricating effect of HA is generally shortlived and the duration of its bioeffects is not predictable. To address these issues, a semisynthetic natural polymer obtained from the CMC combined with $\mathrm{HA}$ has been developed that can generate a new hybrid membrane for use as a tissue barrier $[1,14,21]$. The CMC can cross-link with HA by 1-(3-dimethylaminopropyl)-3-ethylcarbodiimide hydrochloride (EDC) with a various cross-linking degree [22]. This hybrid membrane can thus prolong the drugrelease function. In addition, the issues of lack of mechanical property of CMC when it is applied alone can be solved.

Phellodendron amurense $\operatorname{Rupr}(P$. amurense) is a Chinese herb used to treat different forms of inflammation and pain. Berberine is an active compound of $P$. amurense found in relatively high concentrations which has been shown to possess the antimicrobial [23] and anti-inflammatory [24] properties. While the bark of $P$. amurense contains abundant cellulose [25], whether or not berberine-enriched CMC can be fabricated from the bark of $P$. amurense has not yet been determined.

Accordingly, the aim of this study was to fabricate a novel hydrogel membrane composed of berberine-enriched CMC prepared from the bark of $P$. amurense and HA (PE$\mathrm{CMC} / \mathrm{HA})$. In vitro anti-inflammatory property was evaluated to determine possible clinical applications.

\section{Materials and Methods}

2.1. Physical Property Tests of HA. The particle size distribution of the HA used in this study was determined using a particle size analyzer (90 Plus, Brookhaven Instruments
Corporation, Holtsville, NY, USA). Before testing, the HA sample was diluted to $0.25 \mathrm{mg} / \mathrm{ml}$ with purified water and stirred for $12 \mathrm{hrs}$. The $\mathrm{pH}$ value of the HA and PE-CMC/HA was measured at room temperature using a $\mathrm{pH}$-meter (Model 6173, JENCO Quality Instrument, San Diego, USA). Thermal stability was detected using a thermogravimeter (TGA, TG 209 F3 Tarsus, Netzsch-Gerätebau GmbH, Germany). During the tests, $5 \mathrm{mg}$ samples were heated from room temperature to $700^{\circ} \mathrm{C}$ at a rate of $10^{\circ} / \mathrm{min}$. Thermal decomposition temperatures $\left(T_{d}\right)$ and the residual weight were detected. Kinematic viscosity of the HA was tested using a viscometer (X-420, Cannon Instrument Co., PA, USA). $40 \mathrm{mg}$ samples were added to analytical grade water to bring the concentration of each solution to $0.5 \mathrm{mg} / \mathrm{ml}$. After magnetic stirring for 1 hour, the kinematic viscosity of the test HA was read with a unit of centistokes (cSt).

2.2. Cytotoxicity Test of HA Used in This Study. Testing for cytotoxicity was performed according to international standard ISO10993-5. NIH 3T3 and RAW264.7 macrophage cell lines were used to test the cytotoxicity of the HA and PE-CMC/HA membranes. For HA testing, NIH-3T3 fibroblast cells were seeded onto Petri dishes at a density of 10,000 cells $/ \mathrm{ml}$. Dulbecco's modified Eagle's medium (DMEM, Gibco, Grand Island, NY, USA) supplemented with L-glutamine and $10 \%$ fetal bovine serum was used as culture medium. The cells were incubated at $37^{\circ} \mathrm{C}$ in $5 \% \mathrm{CO}_{2}$ at $100 \%$ humidity. The NIH-3T3 cells cultured with a $2 \%$ dimethyl sulfoxide (DMSO, Sigma-Aldrich, St. louis, MO, USA) was used for a positive control while the cells cultured with DMEM alone were used for negative control. After coculturing with HA for 24 hours, cell viability was determined using the MTT method. Absorbance was measured at 570/690 nm wavelengths using a microplate reader (Model 2020, Anthos Labtec Instruments, Eugendorf, Wals, Austria).

2.3. PE-CMC Preparation. The PE-CMC was prepared following a modified technique from a previous study [26]. The crude $P$. amurense bark extracts containing a high content of berberine were prepared as per the previous report. Then the residue pomace was dried, ground into powder, immersed in $5 \% \mathrm{NaOH}$ (Fisher Scientific, Pittsburgh, PA, USA) for 2 hours at room temperature, and then heated to $90^{\circ} \mathrm{C}$ in $10 \% \mathrm{NaOH}$ for 4 hours. The $\mathrm{NaClO}$ (Acros Organics, Geel, Belgium) : $\mathrm{H}_{2} \mathrm{O}_{2}$ (Acros Organics) $=3: 4$ was used to bleach the substrate and then washed with fresh water. An air suction filler was used to further dry the substrate for 2 hours. The substrate was alkalified at $30^{\circ} \mathrm{C}$ for $60 \mathrm{~min}$ and etherified at $70^{\circ} \mathrm{C}$ for $150 \mathrm{~min}$ in $85 \%$ ethanol. After the substrate was cooled, it was washed twice with $75 \%$ alcohol and an air suction filler was used to obtain the pure CMC substrate. Finally, a freeze-drying machine was used for 3 hours to obtain the dry PE-CMC powder.

2.4. CMC/HA and PE-CMC/HA Membrane Fabrication. The $\mathrm{PE}-\mathrm{CMC} / \mathrm{HA}$ membrane was composed of a PE-CMC and HA base with Polyvinyl alcohol (PVA, Sigma-Aldrich) to form a film, TWEEN80 (MERU Chemical, Taipei, Taiwan) for emulsifying. Sapindus mukorossi seed-extracted oil was 
added for lubrication. The sodium hyaluronic acid (M.W: 2.6 $\times 10^{6} \mathrm{Da}$ ) was purchased from MERU Chemical. The PVA and TWEEN80 were commercially available from SigmaAldrich and MERU Chemical, respectively. First, the PVA was dissolved in distilled water at a concentration of $0.5 \mathrm{~g} / \mathrm{mL}$ at $121^{\circ} \mathrm{C}$ for $30 \mathrm{~min}$. The PE-CMC (10 mg/mL), HA $(30 \mathrm{mg} / \mathrm{mL})$, TWEEN80, seed oil, and berberine-enriched CMC were added and mixed with a magnetic stirrer. When thoroughly mixed, $3 \mathrm{ml}$ of the mixture was moved to a round mold $60 \mathrm{~mm}$ in diameter and $15 \mathrm{~mm}$ in depth. The mold was then put into an oven at $37^{\circ} \mathrm{C}$ for 3 hours to form a dried membrane. In this study, $\mathrm{CMC} / \mathrm{HA}$ fabricated using commercialized CMC (Sigma-Aldrich) and HA using the same method mentioned above was used as control group.

2.5. Mechanical Tests of the Membrane. Before the test, the membrane was cut into a $15 \times 20 \mathrm{~mm}$ rectangle. Mechanical tests of the $\mathrm{PE}-\mathrm{CMC} / \mathrm{HA}$ and $\mathrm{CMC} / \mathrm{HA}$ membranes with various $\mathrm{CMC}: \mathrm{HA}$ ratios $(30: 70,50: 50$, and $60: 40)$ were performed using a universal testing machine (AGS-1000D, Shimadzu, Tokyo, Japan) according to ASTM D 638-08 regulations. Briefly, the samples were fixed $5 \mathrm{~mm}$ from both widths. The crosshead speed was set at $30 \mathrm{~mm} / \mathrm{min}$ and a load was applied until the sample fractured. Tensile strength was determined as the maximum value of the force.

2.6. Morphological Features of the Membrane. To enhance morphological features, $\mathrm{PE}-\mathrm{CMC} / \mathrm{HA}$ and $\mathrm{CMC} / \mathrm{HA}$ membrane surfaces were given a thin coating of palladium gold (IB-2, Hitachi Ltd., Chiyoda, Tokyo, Japan). Ultrastructure images of the samples were observed using scanning electron microscopy (SEM) (Model 2400; Hitachi, Tokyo, Japan).

2.7. Berberine Detection. Berberine content was determined using a NanoDrop UV-Vis Spectrophotometer (ND-1000, Thermo Scientific, Waltham, MA, USA) at $260 \mathrm{~nm}$ wavelength as in a previous study [27]. The calibration curve of the berberine standard (B3251, Sigma-Aldrich) was determined from six concentration points over the range of concentrations ( 37.25 to $1000 \mu \mathrm{g} / \mathrm{mL}$ ) with an $R$ value greater than 0.99 . Before detection, the membranes were dissolved in distilled water to create a solution with a concentration of $500 \mu \mathrm{g} / \mathrm{mL}$. The amounts of berberine released from the tested membranes were calculated from the standard curves.

2.8. Anti-Inflammatory Test of the Membrane. To test the anti-inflammatory properties of the CMC/HA and PECMC/HA membrane, RAW264.7 macrophage cells were seeded into a 96-well plate at a concentration of $4 \times$ $10^{5}$ cells $/ \mathrm{mL}$ and cultivated in an incubator at $37^{\circ} \mathrm{C}$ and $5 \%$ $\mathrm{CO}_{2}$. After incubating for 24 hours, cells were stimulated with $1 \mu \mathrm{g} / \mathrm{mL}$ of lipopolysaccharide (LPS, Sigma-Aldrich) from Escherichia coli strain 055: B5 and HA/CMC membrane extracted medium. The N-nitro-L-arginine-methyl ester (LNAME, Sigma-Aldrich) with a concentration $1 \mathrm{mM}$ was used as a positive control. The nitric oxide concentration produced by RAW 264.7 cells was determined through Griess assay. Briefly, an equal volume of Griess reagent (N5751, Sigma) was mixed with the culture supernatant and color development was measured at $530 \mathrm{~nm}$ using a microplate reader (EZ Read 400, Biochrom, Holliston, MA, USA). Anti-inflammatory activity was presented in terms of NO production inhibition percentage.

2.9. Statistical Analysis. For cell viability tests, mean values and standard deviations of each measurement were recorded. To evaluate the changes between the samples and control, one-way analysis of variance (ANOVA) (SPSS Inc., Chicago, IL, USA) with Tukey's post hoc was performed. A $p$ value lower than 0.05 was considered statistically significant.

\section{Results}

3.1. Physical Properties of HA. The HA particles had two populations in size. As shown in Figure 1, HA particles sizes are concentrated at $100-250 \mu \mathrm{m}$ and $600-900 \mu \mathrm{m}$. The kinematic viscosity of $\mathrm{HA}$ increases as a function of concentration (Figure 1(b)). When the concentration of HA increased from 0.1 to $0.8 \mathrm{mg} / \mathrm{ml}$, the kinematic viscosity of the HA increased from 2.93 to 36.31 . Figure 1(c) illustrates the thermography of the HA used in this study. The decomposition temperature $\left(T_{d}\right)$ of test $\mathrm{HA}$ was $71.75^{\circ} \mathrm{C}$. The residual weight was $25.82 \%$ at $700^{\circ} \mathrm{C}$.

3.2. Cytotoxicity Test of HA Used in This Study. Figure 2 shows the results of cytotoxic tests of HA used in this study. The viability of NIH-3T3 cells cultured with 2\% DMSO was significantly reduced by $20 \%$. Growth analysis of NIH-3T3 cells cultured with HA with concentrations up to $0.4 \mathrm{mg} / \mathrm{ml}$ showed no relevant viability inhibition. That is, under the given conditions no cytotoxic substrates were released from the HA material.

3.3. Berberine Detection. The UV-Vis spectrum of standard berberine is shown in Figure 3(a). There are two absorption bands at around 250 and $350 \mathrm{~nm}$ and a weak band at about $430 \mathrm{~nm}$. The shape of the absorption spectrum of the $P$. amurense bark extract is similar to berberine standard. The sample also exhibited two absorption bands at around 250 and $350 \mathrm{~nm}$. However, the band at about $430 \mathrm{~nm}$ was not significant. The 250 and $350 \mathrm{~nm}$ bands can also be detected in fabricated $\mathrm{PE}-\mathrm{CMC} / \mathrm{HA}$ as with $P$. amurense extract (Figure 3(b)). Figure 4 shows the quantitative results of UV detection at a wavelength of $260 \mathrm{~nm}$. When the fabricated PE-CMC/HA membrane was dissolved in water, significant berberine release was confirmed at a concentration of $660 \mu \mathrm{g} / \mathrm{ml}$.

3.4. Mechanical Tests. Figure 5 shows the mechanical tests of the $\mathrm{CMC} / \mathrm{HA}$ membranes fabricated in this study. The membranes exhibited a critical plastic characteristic. The ultimate strength of the $\mathrm{CMC} / \mathrm{HA}$ decreases when increasing the amount of HA. For samples mixed to a ratio of $30: 70$, $50: 50$, and $60: 40$, the ultimate strengths were $1.57 \pm 0.37$, $2.06 \pm 0.13$, and $2.36 \pm 0.13 \mathrm{kgf}$, respectively. In contrast, the ultimate displacement for the $\mathrm{CMC} / \mathrm{HA}$ increases when 


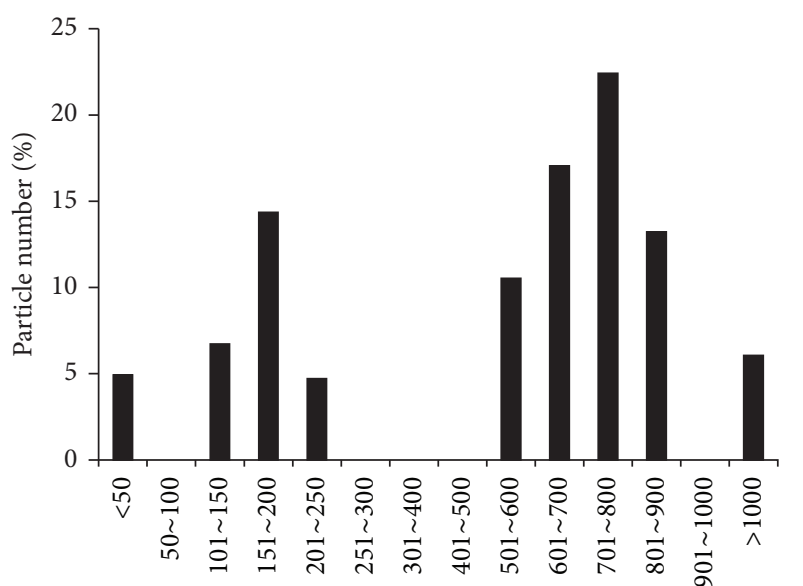

Particle size (nm)

(a)

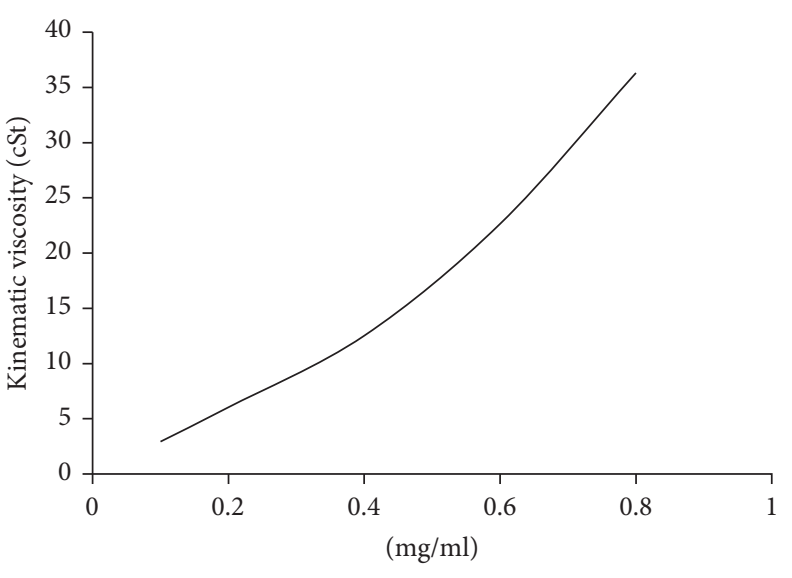

(b)

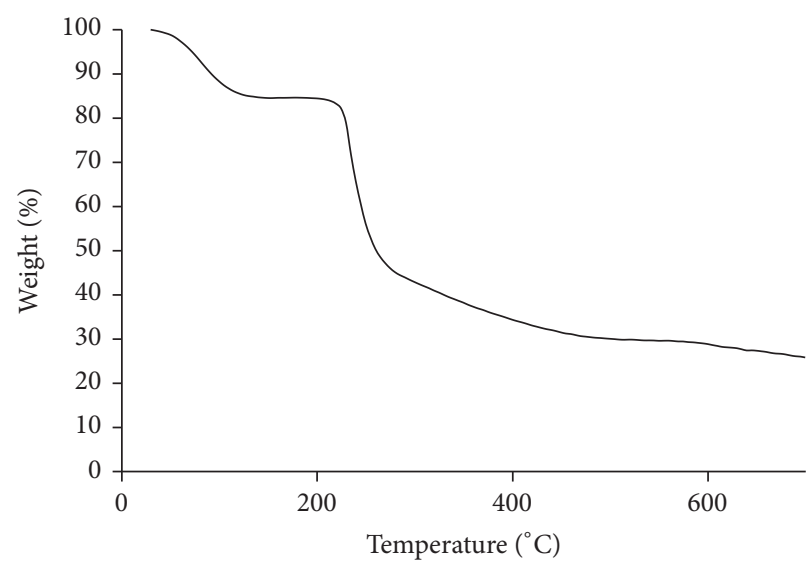

(c)

FIgURE 1: HA physical properties. (a) HA particle diameter distributions. (b) HA kinematic viscosity. (c) HA TGA patterns.

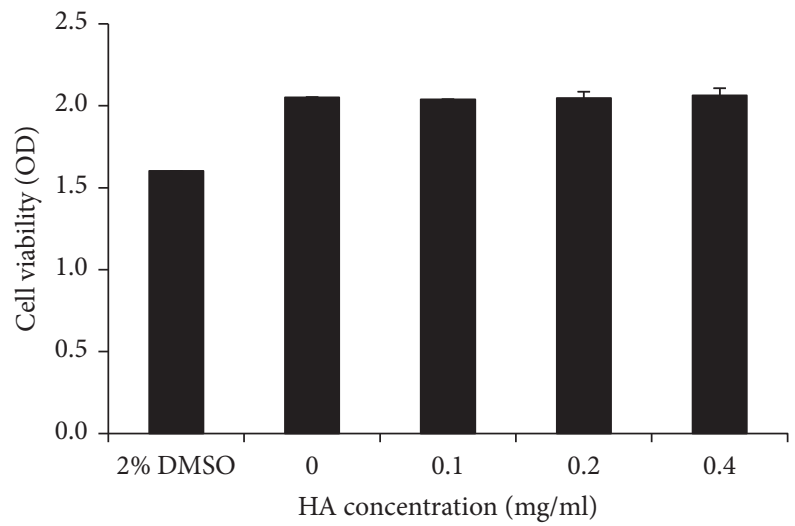

FIGURE 2: Cytotoxicity tests for the HA used in this study.

the HA amount was increased. The ultimate displacement readings for the $30: 70,50: 50$, and $60: 40 \mathrm{CMC} / \mathrm{HA}$ are $12.04 \pm 2.14,11.78 \pm 1.22$, and $10.76 \pm 0.68 \mathrm{~mm}$, respectively. The addition of $P$. amurense extract reduces both ultimate strength and elongation of the membrane. The ultimate strength and displacement of the $\mathrm{PE}-\mathrm{CMC} / \mathrm{HA}$ membrane were $1.42 \pm 0.32 \mathrm{kgf}$ and $11.75 \pm 1.57 \mathrm{~mm}$, respectively. Considering the plasticity, deformation capability is more important than strength for the purpose of this study. Meanwhile, the HA amount can have a biological effect on wound 


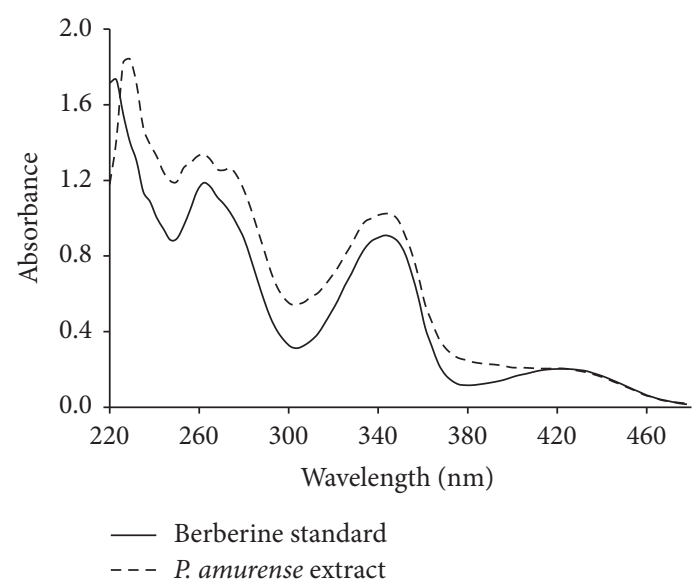

(a)

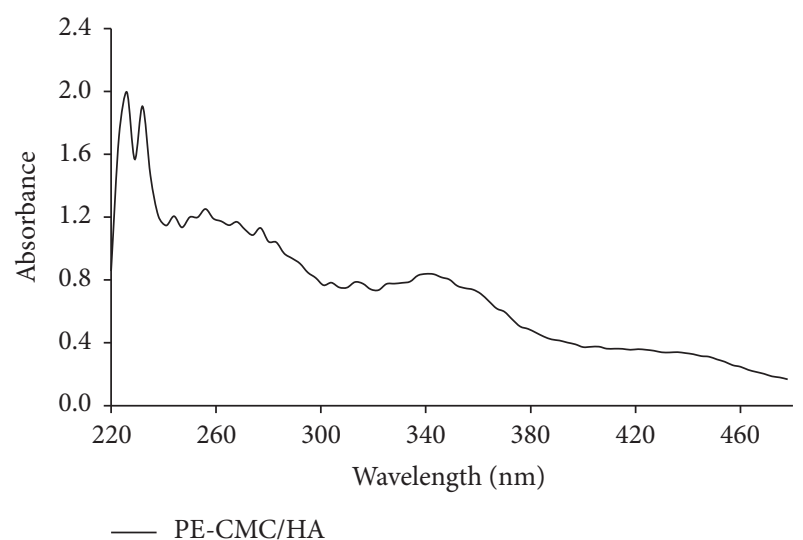

(b)

FIgURE 3: UV-Vis absorption spectra of (a) berberine standard, P. amurense extract, and (b) the fabricated PE-CMC/HA membrane.

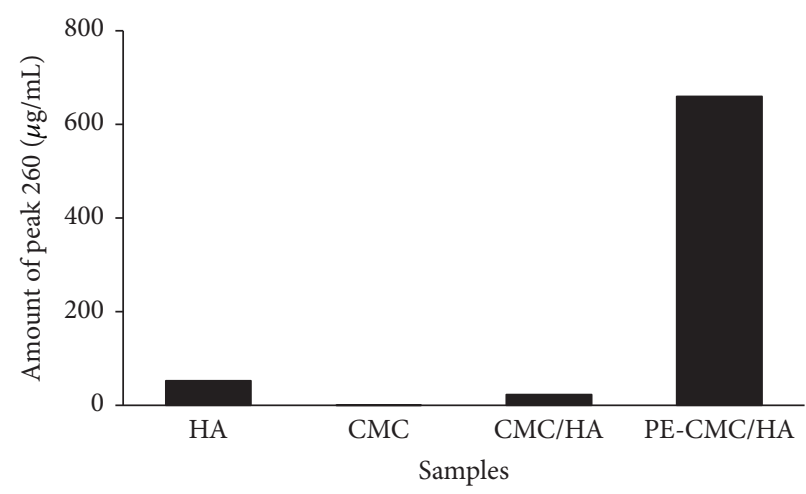

FIGURE 4: UV-Vis detection at a wavelength of $260 \mathrm{~nm}$.

healing. Since the HA amount has a markedly positive effect on membrane plasticity, a membrane incorporating $70 \mathrm{wt} \%$ $\mathrm{HA}$ was used for fabricating the PE-CMC/HA used in the following biofunction tests.

3.5. Surface Topographies of the Membrane. SEM images of the fabricated $\mathrm{CMC} / \mathrm{HA}$ and $\mathrm{PE}-\mathrm{CMC} / \mathrm{HA}$ samples revealed different surface topographies. The 30:70 CMC/HA sample was porous with any uniformly shaped holes observed (Figure 6(a)). For the 50:50 CMC/HA sample, the surface porosity was significantly lower (Figure 6(b)). Interestingly, the $60: 40 \mathrm{CMC} / \mathrm{HA}$ sample is a nonporous material. Only the $60: 40 \mathrm{CMC} / \mathrm{HA}$ sample had a smooth, planar texture (Figure 6(c)). The porosity of the PE-CMC/HA surface was also observable (Figure 6(d)). However, the holes were irregular in shape and significantly larger in pore size than those of $\mathrm{CMC} / \mathrm{HA}$ samples.

3.6. Anti-Inflammatory Test. As shown in Figure 7, when the cell was treated with LPS $(1 \mu \mathrm{g} / \mathrm{ml})$, obvious morphological changes were found. Furthermore, the cells cultured with CMC-HA and PE-CMC/HA did not have altered morphological changes due to LPS treatment. However, CMC-HA and $\mathrm{PE}-\mathrm{CMC} / \mathrm{HA}$ significantly affected the NO release of the LPS- treated cells. The NO release of the sample was normalized by comparing the measured data to the untreated sample. Significant reductions in NO release $(8.56 \%)$ were noted in the LNAME group when compared to the blank control (Figure 8). That is, the inhibition ratio of NO release for L-NAME was 91.44\%. When the LPS loaded RAW 264.7 cells were treated with the composite fabricated from commercialized CMC and HA the NO release was reduced to $54.11 \%$. When $P$. amurense extract was added to the fabricated PE-CMC/HA and used in culture with the LPS loaded RAW 264.7 cells, the detected NO was decreased to $39.73 \%$ compared to the blank control.

\section{Discussion}

The preclinical evaluation demonstrated that HA/CMC is nontoxic, nonmutagenic, nonimmunogenic, nonirritating, and nonpyrogenic [28]. A previous study indicated that $\mathrm{HA} / \mathrm{CMC}$ did not induce an inflammatory cytokine response [29]. Thus HA/CMC can be not only an antiadhesive material but also a material for drug release. Since infection is the major reason for GBR membrane failure in clinical application [30], developing GBR membranes that can perform localized drug delivery to prevent infection is an important 


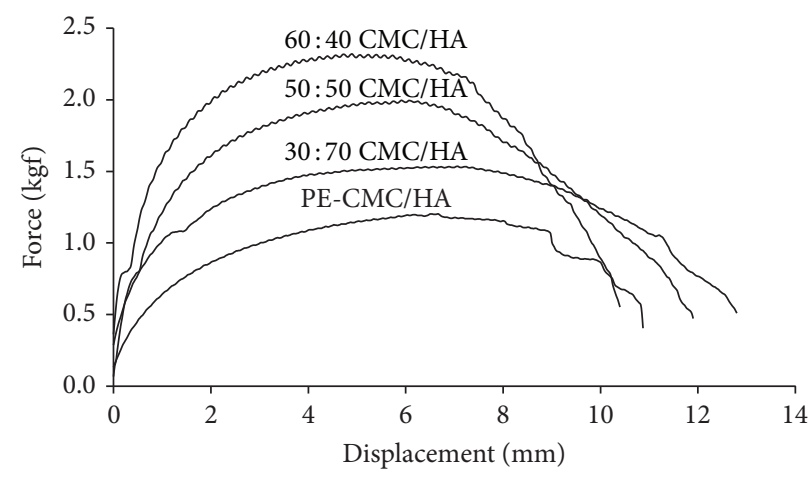

Figure 5: Mechanical tests of the PE-CMC/HA and CMC/HA membranes at various mix ratios.

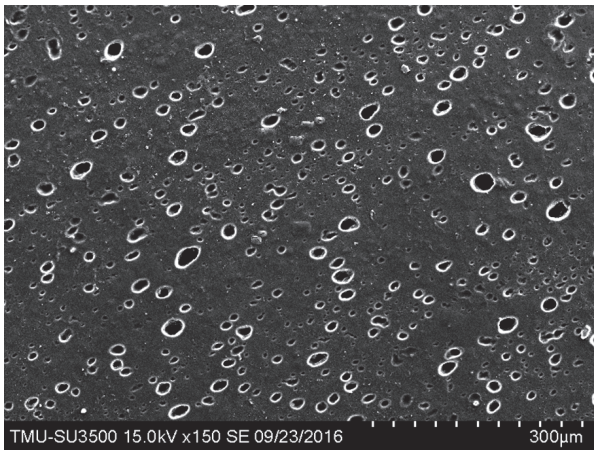

(a)

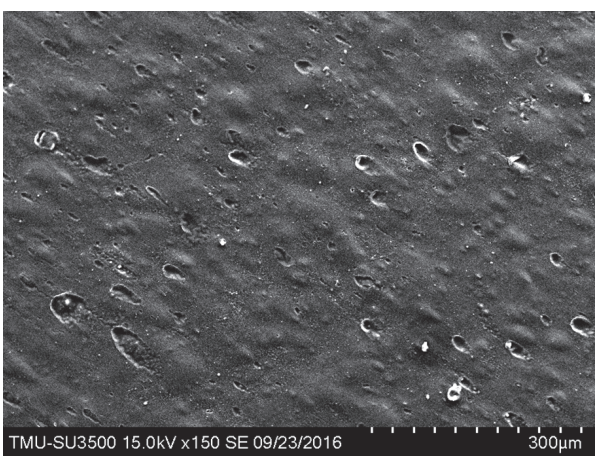

(c)

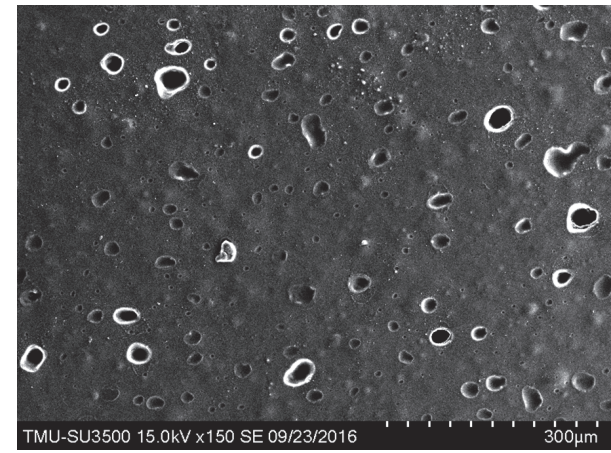

(b)

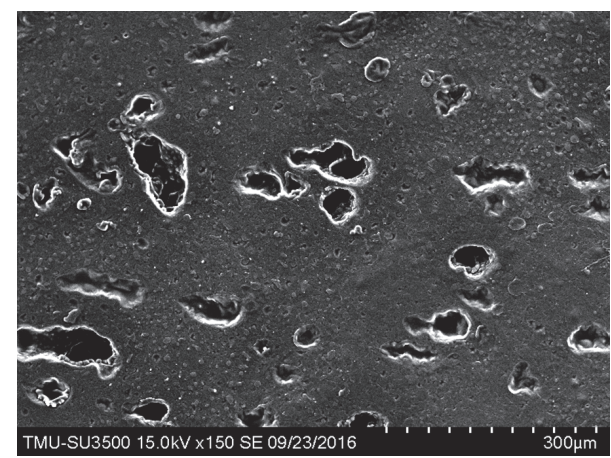

(d)

FIgURE 6: Scanning electron microscopy (SEM) images of the CMC/HA membranes surface at various mix ratios: (a) $30: 70$, (b) 50:50, and (c) $60: 40$. (d) shows a topographical image of the fabricated PE-CMC/HA surface.

biomaterials engineering issue. In 2012, Epstein-Barash et al. fabricated a hydrogel by cross-linking CMC and HA as a protein/peptide release system [22]. For clinical usage, this hybrid hydrogel has several advantages, such as slow protein release, ease of handling, and the ability to be delivered via minimally invasive means. In addition, fabrication of such a $\mathrm{CMC} / \mathrm{HA}$ hydrogel does not require chemical additives or a source of energy source.

The main bioactive component of $P$. amurense is berberine. In this study, the extract of $P$. amurense was added to the fabricated $\mathrm{PE}-\mathrm{CMC} / \mathrm{HA}$ as a released substrate. As shown in Figure 4, the berberine-specific absorbance band at $260 \mathrm{~nm}$ was detected as in a previous study [31]. This result indicates that our PE-CMC/HA membrane can operate as a berberinereleased system. It is well known that berberine exhibits specific pharmacological properties, such as being antimicrobial, antiparasitic, anti-inflammatory, and anticytotoxic properties $[23,24,27]$. As shown in Figure 8, the fabricated PE$\mathrm{CMC} / \mathrm{HA}$ significantly reduced inflammatory cytokine (NO) release. According to this result, it is reasonable to suggest that the current PE-CMC/HA membrane can be used as an antibacterial and anti-inflammatory drug-release system.

It has been reported that the strength of a membrane is determined by the size, shape, and density of the structure's 

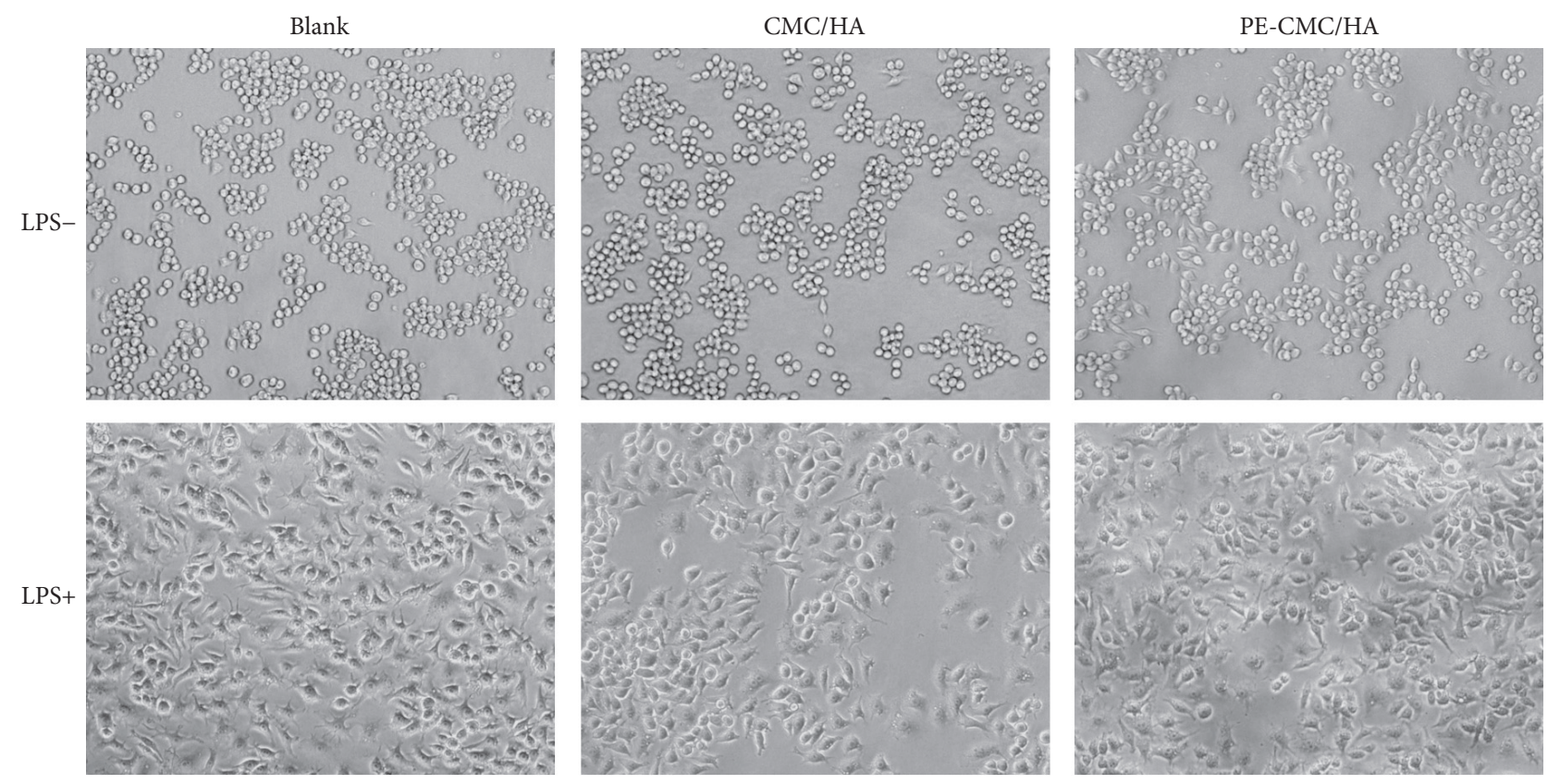

FIgURE 7: Microscopy of LPS-treated and untreated RAW 264.7 cells. The addition of CMC-HA and PE-CMC/HA did not alter the morphology of the cells.

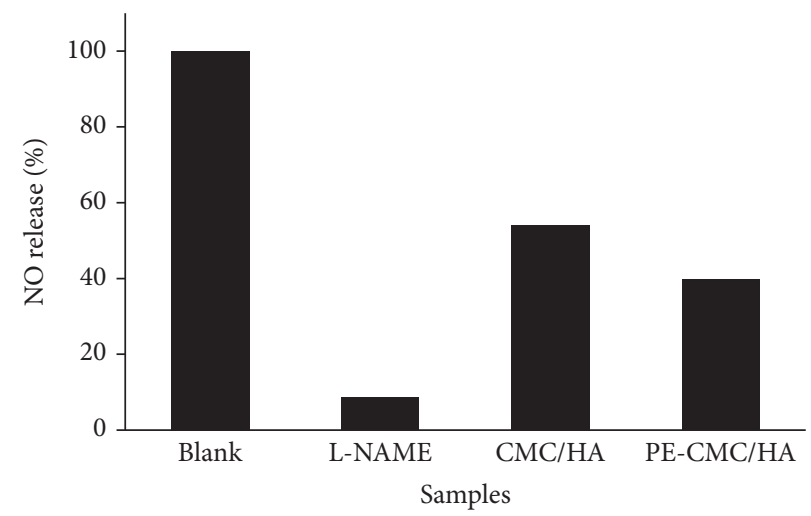

FIGURE 8: Normalized NO release of the LPS-induced RAW 264.7 cells. The fabricated CMC-HA and PE-CMC/HA tended to reduce NO release.

micropores/nanopores [32]. Since the strength of a membrane decreases as the size and porosity of the pores increase, it is not surprising that the mechanical property of current $\mathrm{CMC} / \mathrm{HA}$ membrane is strongly correlated to the CMC-toHA mix ratio (Figure 5). From Figure 5, we can see that higher CMC concentrations result in a higher ultimate membrane strength. This is because the increase of the CMC ratio tends to decrease the porosity of the membrane (Figure 6). This result confirmed a previous finding that cellulose-based hydrogels lack good mechanical proprieties for clinical use [14]. In contract, the amount of HA has a markedly positive effect on the plasticity of the membrane (Figure 5). This is because the HA is a highly viscous gel (Figure 1(b)) allowing the water-dissolved PE-CMC/HA fabricated in this study that can be injected into tissues and coating to follow the contours of underlying tissues.
According to the specific characteristic of the PE$\mathrm{CMC} / \mathrm{HA}$, the membrane can be used for extensive biomedical applications. For example, the fabricated PE-CMC/HA membrane has potential as a candidate for treating vaginal infections. The characteristics of the vaginal epithelium change depending on variations in the concentration of estrogenic and progestational hormones. During the fertile period, the vagina is soft and elastic due to the balance mechanism of the vaginal epithelium that maintains appropriate hydration and lubrication. In some cases, such as during lactation, menopause, after pregnancy, with the use of oral contraceptives, or when under stress, this balance may be disturbed. In such situations, signs of vaginal dryness, burning sensations, or itching may be observed due to insufficient vaginal lubrication. It is well known that the major ability of $\mathrm{HA}$ is to hold water and retain a balanced amount of moisture 
[33]. As shown in Figure 6, the ultrastructure images of the PE-CMC/HA membrane fabricated in this study have a porous structure. Such porosity moisturizes the membrane. In addition, HA exhibits a number of healing properties, including the facilitation of cell migration and differentiation during tissue formation and repair [33]. Thus, it is efficient and safe to use HA to treat vaginal dryness in postmenopausal women [34].

However, HA is quickly degraded by enzymes and absorption by tissue. This means HA cannot be used for long-term treatment. Mixing HA with CMC not only delays the absorption of HA but also prolongs the duration of the antimicrobial and anti-inflammatory effects of HA and berberine $[35,36]$. Park et al. (2011) indicated that the peptide/protein release profiles of the CMC/HA can be easily tuned by adjusting its cross-linker density [21]. In this study, cross-linker was not added during fabrication of the PE$\mathrm{CMC} / \mathrm{HA}$. Understanding how the degree of cross-linking affects the release efficiency of berberine and the mechanical properties of the membrane were limitations of this study.

\section{Conclusion}

In conclusion, the PE-CMC/HA membrane fabricated in this study is a berberine release system to provide antibacterial and anti-inflammatory functions. The excellent viscosity of $\mathrm{PE}-\mathrm{CMC} / \mathrm{HA}$ makes it a possible candidate for manufacturing hydrogel for treating infections of disease.

\section{Competing Interests}

The authors have declared that there is no conflict of interests.

\section{Authors' Contributions}

Haw-Ming Huang and Chun-Han Ko contributed equally to this work.

\section{Acknowledgments}

Authors would like to express their sincere appreciation to Lake Forest Co., Guizhou, China, which provided the bark of $P$. amurense tree and the great support of the research resources.

\section{References}

[1] L. Picaud, B. Thibault, E. Mery et al., "Evaluation of the effects of hyaluronic acid-carboxymethyl cellulose barrier on ovarian tumor progression," Journal of Ovarian Research, vol. 7, no. 1, article no. 40, 2014.

[2] J. Liu and D. G. Kerns, "Mechanisms of guided bone regeneration: a review," The Open Dentistry Journal, vol. 8, supplement 1, pp. 56-65, 2014.

[3] D. Buser, K. Dula, U. Belser, H. P. Hirt, and H. Berthold, "Localized ridge augmentation using guided bone regeneration. 1. Surgical procedure in the maxilla," The International Journal of Periodontics and Restorative Dentistry, vol.13, no. 1, pp. 29-45, 1993.
[4] W. Becker, C. Dahlin, U. Lekholm et al., "Five-year evaluation of implants placed at extraction and with dehiscences and fenestration defects augmented with ePTFE membranes: results from a prospective multicenter study," Clinical implant dentistry and related research, vol. 1, no. 1, pp. 27-32, 1999.

[5] E. E. Machtei, "The effect of membrane exposure on the outcome of regenerative procedures in humans: a meta-analysis," Journal of Periodontology, vol. 72, no. 4, pp. 512-516, 2001.

[6] M. Simion, M. Baldoni, P. Rossi, and D. Zaffe, "A comparative study of the effectiveness of e-PTFE membranes with and without early exposure during the healing period," The International Journal of Periodontics and Restorative Dentistry, vol. 14, no. 2, pp. 166-180, 1994.

[7] N. U. Zitzmann, R. Naef, and P. Schärer, "Resorbable versus nonresorbable membranes in combination with Bio-Oss for guided bone regeneration," International Journal of Oral \& Maxillofacial Implants, vol. 12, no. 6, pp. 844-852, 1997.

[8] A. Piattelli, A. Scarano, F. Coraggio, and S. Matarasso, "Early tissue reactions to polylactic acid resorbable membranes: a histological and histochemical study in rabbit," Biomaterials, vol. 19, no. 10, pp. 889-896, 1998.

[9] H.-L. Wang and W. J. Carroll, "Guided bone regeneration using bone grafts and collagen membranes," Quintessence International, vol. 32, no. 7, pp. 504-515, 2001.

[10] D. Rothamel, F. Schwarz, A. Sculean, M. Herten, W. Scherbaum, and J. Becker, "Biocompatibility of various collagen membranes in cultures of human PDL fibroblasts and human osteoblast-like cells," Clinical Oral Implants Research, vol. 15, no. 4, pp. 443-449, 2004.

[11] K. W. Owens and R. A. Yukna, "Collagen membrane resorption in dogs: a comparative study," Implant Dentistry, vol. 10, no. 1, pp. $48-58,2001$.

[12] H. Geckil, F. Xu, X. Zhang, S. Moon, and U. Demirci, "Engineering hydrogels as extracellular matrix mimics," Nanomedicine, vol. 5, no. 3, pp. 469-484, 2010.

[13] R. M. A. Domingues, M. E. Gomes, and R. L. Reis, "The potential of cellulose nanocrystals in tissue engineering strategies," Biomacromolecules, vol. 15, no. 7, pp. 2327-2346, 2014.

[14] D. Pasqui, P. Torricelli, M. De Cagna, M. Fini, and R. Barbucci, "Carboxymethyl cellulose-hydroxyapatite hybrid hydrogel as a composite material for bone tissue engineering applications," Journal of Biomedical Materials Research Part A, vol. 102, no. 5, pp. 1568-1579, 2014.

[15] N. Sagar, A. K. Pandey, D. Gurbani et al., "In-vivo efficacy of compliant 3D nano-composite in critical-size bone defect repair: a six month preclinical study in rabbit," PLoS ONE, vol. 8, no. 10, Article ID e77578, 2013.

[16] P. Korn, M. C. Schulz, V. Hintze et al., "Chondroitin sulfate and sulfated hyaluronan-containing collagen coatings of titanium implants influence peri-implant bone formation in a minipig model," Journal of Biomedical Materials Research-Part A, vol. 102, no. 7, pp. 2334-2344, 2014.

[17] C. R. Correia, L. S. Moreira-Teixeira, L. Moroni et al., "Chitosan scaffolds containing hyaluronic acid for cartilage tissue engineering," Tissue Engineering_Part C: Methods, vol. 17, no. 7, pp. 717-730, 2011.

[18] P. Dahiya and R. Kamal, "Hyaluronic acid: a boon in periodontal therapy," North American Journal of Medical Sciences, vol. 5, no. 5, pp. 309-315, 2013.

[19] J. Kablik, G. D. Monheit, L. Yu, G. Chang, and J. Gershkovich, "Comparative physical properties of hyaluronic acid dermal fillers," Dermatologic Surgery, vol. 35, pp. 302-312, 2009. 
[20] H. Jentsch, R. Pomowski, G. Kundt, and R. Göcke, "Treatment of gingivitis with hyaluronan," Journal of Clinical Periodontology, vol. 30, no. 2, pp. 159-164, 2003.

[21] J. S. Park, J. H. Lee, C. S. Han, D. W. Chung, and G. Y. Kim, "Effect of hyaluronic acid-carboxymethylcellulose solution on perineural scar formation after sciatic nerve repair in rats," Clinics in Orthopedic Surgery, vol. 3, no. 4, pp. 315-324, 2011.

[22] H. Epstein-Barash, C. F. Stefanescu, and D. S. Kohane, "An in situ cross-linking hybrid hydrogel for controlled release of proteins," Acta Biomaterialia, vol. 8, no. 5, pp. 1703-1709, 2012.

[23] C.-L. Kuo, C.-W. Chi, and T.-Y. Liu, "The anti-inflammatory potential of berberine in vitro and in vivo," Cancer Letters, vol. 203, no. 2, pp. 127-137, 2004.

[24] Z.-B. Yi, Y. Yu, Y.-Z. Liang, and B. Zeng, "Evaluation of the antimicrobial mode of berberine by LC/ESI-MS combined with principal component analysis," Journal of Pharmaceutical and Biomedical Analysis, vol. 44, no. 1, pp. 301-304, 2007.

[25] M. A. K. Azad, S. Yokota, F. Ishiguri, and N. Yoshizawa, "Plant regeneration from mesophyll protoplasts of a medicinal plant, Phellodendron amurense rupr.," In Vitro Cellular \& Developmental Biology-Plant, vol. 42, no. 6, pp. 502-507, 2006.

[26] P. Rojsanga, W. Gritsanapan, and L. Suntornsuk, "Determination of berberine content in the stem extracts of Coscinium fenestratum by TLC densitometry," Medical Principles and Practice, vol. 15, no. 5, pp. 373-378, 2006.

[27] M. S. Díaz, M. L. Freile, and M. I. Gutiérrez, "Solvent effect on the UV/Vis absorption and fluorescence spectroscopic properties of berberine," Photochemical and Photobiological Sciences, vol. 8, no. 7, pp. 970-974, 2009.

[28] J. W. Burns, M. J. Colt, L. S. Burgees, and K. C. Skinner, "Preclinical evaluation of Seprafilm bioresorbable membrane," The European Journal of Surgery. Supplement, vol. 577, pp. 4048, 1997.

[29] K. Uchida, K. Otake, M. Inoue et al., "Bacteriostatic effects of hyaluronan-based bioresorbable membrane," Surgical Science, vol. 2, no. 9, pp. 431-436, 2011.

[30] J. Xue, M. He, Y. Niu et al., "Preparation and in vivo efficient anti-infection property of GTR/GBR implant made by metronidazole loaded electrospun polycaprolactone nanofiber membrane," International Journal of Pharmaceutics, vol. 475, no. 1-2, pp. 566-577, 2014.

[31] G. Srinivasan, K. Unnikrishnan, A. Rema Shree, and I. Balachandran, "HPLC estimation of berberine in Tinospora cordifolia and Tinospora sinensis," Indian Journal of Pharmaceutical Sciences, vol. 70, no. 1, pp. 96-99, 2008.

[32] Y. Liu and X. Chen, "Mechanical properties of nanoporous graphene membrane," Journal of Applied Physics, vol. 115, no. 3, Article ID 034303, 2014.

[33] J. Necas, L. Bartosikova, P. Brauner, and J. Kolar, "Hyaluronic acid (hyaluronan): a review," Veterinarni Medicina, vol. 53, no. 8, pp. 397-411, 2008.

[34] J. Chen, L. Geng, X. Song et al., "Evaluation of efficacy and safety of Hyaluronic acid vaginal gel (Hyalofemme) for improvement of vaginal dryness A multicenter, randomized, open, positive and parallel controlled clinical trial," The Journal of Sexual Medicine, vol. 10, no. 6, pp. 1575-1584, 2013.

[35] M. Yamamoto, N. Endo, M. Ito et al., "Novel polysaccharidederived hydrogel prevents perineural adhesions in a rat model of sciatic nerve adhesion," Journal of Orthopaedic Research, vol. 28, no. 3, pp. 284-288, 2010.
[36] S. Ișik, S. Öztürk, S. Gürses et al., "Prevention of restrictive adhesions in primary tendon repair by HA-membrane: experimental research in chickens," British Journal of Plastic Surgery, vol. 52, no. 5, pp. 373-379, 1999. 


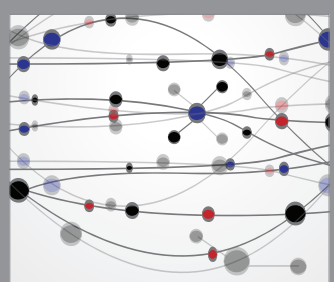

The Scientific World Journal
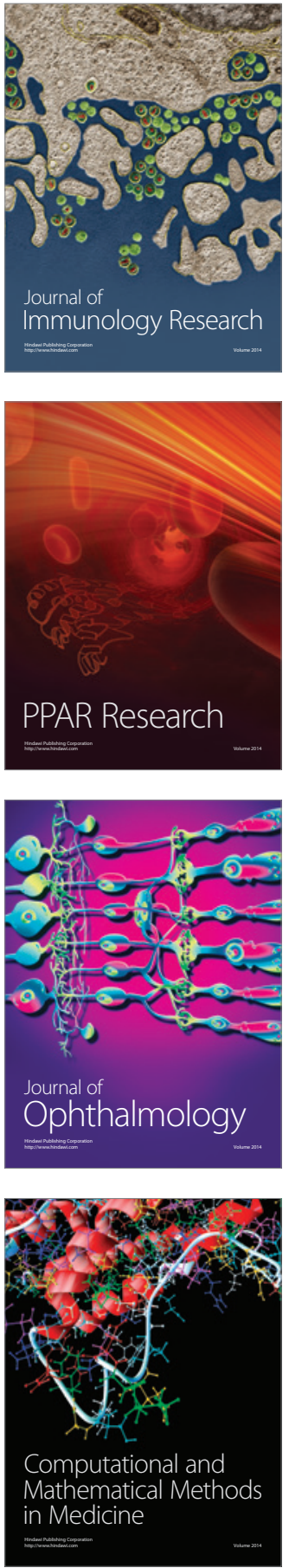

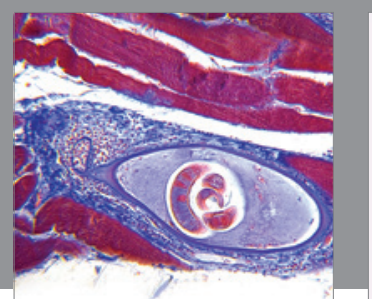

Gastroenterology Research and Practice

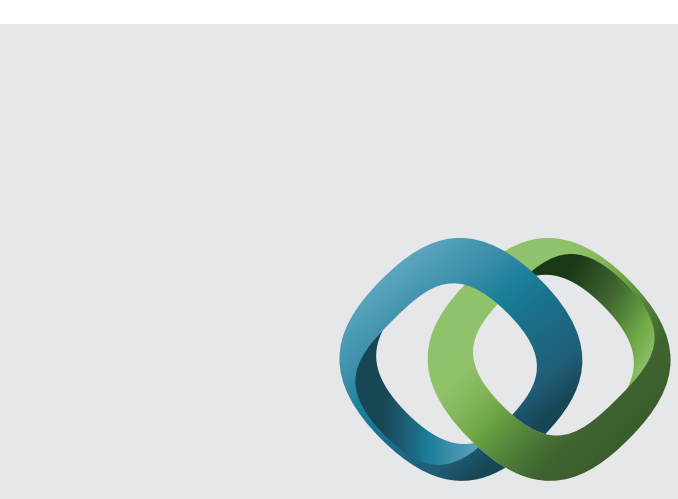

\section{Hindawi}

Submit your manuscripts at

http://www.hindawi.com
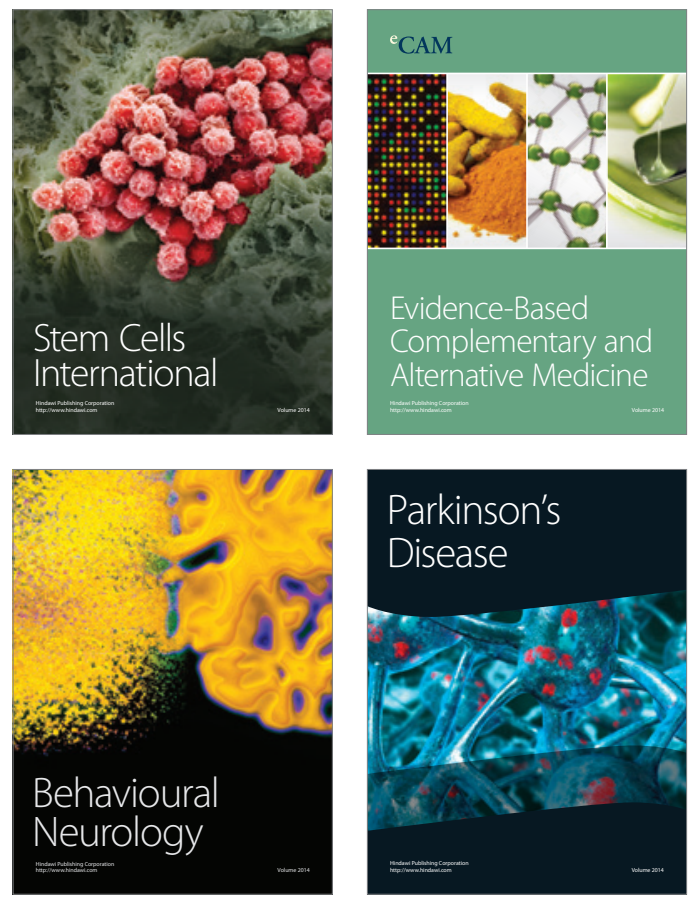
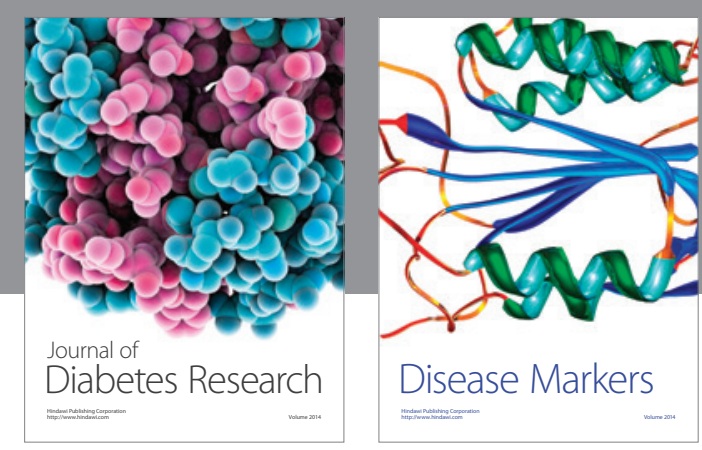

Disease Markers
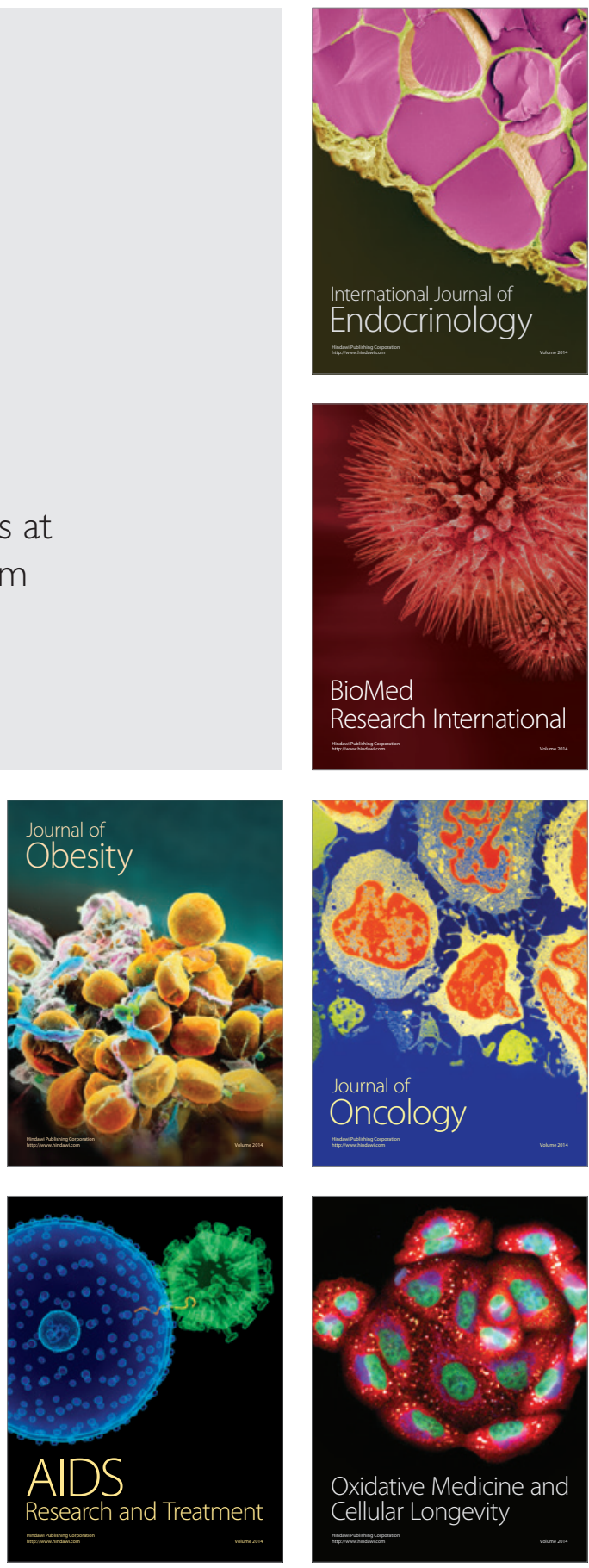